\title{
Dynamic Analysis of the Expression of the TGF//SMAD2 Pathway and CCN2/CTGF during Early Steps of Tooth Development
}

\author{
Marcos S. Pacheco ${ }^{a}$ Alice H. Reis ${ }^{a}$ Diego P. Aguiar ${ }^{a}$ Karen M. Lyons ${ }^{b}$ \\ José G. Abreu ${ }^{\mathrm{a}}$ \\ a Departamento de Anatomia, Instituto de Ciências Biomédicas, Universidade Federal do Rio de Janeiro, \\ Rio de Janeiro, Brazil; b Department of Orthopedic Surgery, Department of Molecular, Cell and Developmental \\ Biology, University of California, Los Angeles, Los Angeles, Calif., USA
}

\section{Key Words}

CCn2 null mouse $\cdot$ CTGF/CCN2 - Growth factor . Epithelium-mesenchyme interaction - TGF $\beta / S M A D 2$.

Odontogenesis

\begin{abstract}
Background/Aims: CCN2 is present during tooth development. However, the relationship between CCN2 and the transforming growth factor $\beta$ (TGF $\beta$ )/SMAD2/3 signaling cascade during early stages of tooth development is unclear. Here, we compare the expression of CCN2 and TGF 3 / SMAD2/3 components during tooth development, and analyze the functioning of TGF $\beta / S M A D 2 / 3$ in wild-type (WT) and $\mathrm{Ccn} 2$ null $\left(\mathrm{CCn}^{-/-}\right)$mice. Methods: Coronal sections of mice on embryonic day (E)11.5, E12.5, E13.5, E14.5 and E18.5 from WT and $\mathrm{Ccn}^{-/-}$were immunoreacted to detect CCN2 and components of the TGF $\beta$ signaling pathway and assayed for 5'-bromo-2'-deoxyuridine immunolabeling and proliferating cell nuclear antigen immunostaining. Results: CCN2 and TGF $\beta$ signaling components such as TGF $\beta 1$, TGF $\beta$ receptor II, SMADs2/3 and SMAD4 were expressed in inducer tissues during early stages of tooth development. Proliferation analysis in these areas showed that epithelial cells proliferate less than mesenchymal cells from E11.5 to E13.5, while at E14.5 they proliferate more than mesenchymal cells. We did not find a correlation between functioning of the TGF $\beta 1$ cascade and CCN2 expression because $\mathrm{C} \mathrm{Cn}^{-/-}$mice
\end{abstract}

showed neither a reduction in SMAD2 phosphorylation nor a difference in cell proliferation. Conclusion: CCN2 and the TGF $\beta / S M A D 2 / 3$ signaling pathway are active in signaling centers of tooth development where proliferation is dynamic, but these mechanisms may act independently.

Copyright $\odot 2007$ S. Karger AG, Base

\section{Introduction}

The developing tooth in the mouse is widely used as a model to study signaling cascades that rule out positional information and guide morphogenesis and cellular

\section{Abbreviations used in this paper}

BMP bone morphogenetic protein

BrdU 5'-bromo-2'-deoxyuridine

CCN2 (also known as CTGF)

CTGF connective tissue growth factor

E embryonic day

PBS phosphate-buffered saline

PCNA proliferating cell nuclear antigen

SMAD2P phospho-SMAD2

TGF $\beta$ transforming growth factor $\beta$

TGF $\beta$ RI transforming growth factor receptor I

TGFBRII transforming growth factor receptor II

WT wild type

\section{KARGER}

Fax +4161306 1234

E-Mail karger@karger.ch

www.karger.com
(C) 2007 S. Karger AG, Basel

$1422-6405 / 08 / 1873-0199 \$ 24.50 / 0$

Accessible online at:

www.karger.com/cto
Dr. José Garcia Abreu

Departamento de Anatomia, Instituto de Ciências Biomédicas

Universidade Federal do Rio de Janeiro, Bloco F sala 09

Rio de Janeiro 21949-590 (Brazil)

Tel. +55 212562 6486, Fax +55 212290 0587, E-Mail garciajr@anato.ufrj.br 
differentiation [reviewed by Thesleff, 2003]. Tooth development is a very dynamic morphogenetic process first detected on embryonal day (E) 11.5 in mice as a morphological thickening of the oral epithelium, known as dental lamina. At E13.5, the dental lamina invaginates into the underlying mesenchyme of the first branchial arch, thereby forming epithelial buds in the so-called bud stage. During this stage, mesenchymal cells accumulate around the bud and form the dental papilla. After the bud stage, the epithelial compartment undergoes specific folding during the cap (E14.5) and bell stage (E15.5) [Thesleff, 2003].

Members of the transforming growth factor $\beta$ (TGF $\beta$ ) superfamily such as TGF $\beta 1,2$ and 3 are expressed during tooth development and control important events during tooth and jaw development [Chai et al., 1994]. TGF $\beta$ is a secreted growth factor implicated in bone formation and tissue repair and has been implicated in epithelial-mesenchymal interactions [Heikinheimo et al., 1993; Heldin et al., 1997] controlling cell growth, differentiation, apoptosis and extracellular matrix formation [Fitzpatric et al., 1990; Millan et al., 1991; Massague et al., 1997].

The TGF $\beta$ signaling pathway initiates cellular actions through activation of TGF $\beta$ receptor (TGF $\beta R$ ) II, which has intrinsic serine/threonine kinase activity and phosphorylates TGF $\beta R I$ in its GS domain [Wrana et al., 1994; Massague et al., 1997]. TGF $\beta R I$ associates with and phosphorylates intracellular proteins called SMAD2/3 in a manner dependent on TGF $\beta$ RII phosphorylation [Abdollah et al., 1997; Nakao et al., 1997]. Phosphorylated SMAD2/3 forms hetero-oligomers with SMAD4, which in turn translocate into the nucleus and activate transcriptional responses [Wu et al., 2001].

During odontogenesis, TGF $\beta$ has been shown to modulate epithelial growth and proliferation [Chai et al., 2003]. TGF $\beta$ s negatively regulate dental epithelium promoting alterations in size and shape of teeth, as demonstrated in experiments where TGF $\beta$ is added to teeth in culture, or when its receptor is inhibited or when attenuation of Smad2 occurs [Chai et al., 1994, 1999; Ito et al., 2001]. Thus the fine modulation of TGF $\beta$ s in the extracellular space as well as the access of its receptor is very important to the process to tooth development.

One of the targets of TGF $\beta$ signaling is the matricellular protein CCN2 (also known as connective tissue growth factor, CTGF). CCN2 has been implicated in adhesion, migration, extracellular matrix modulation, skeletogenesis, angiogenesis and wound healing [Moussad and Brigstock, 2000; Ivkovick et al., 2003]. CCN2 is a member of the CCN [CYR61 (cysteine-rich 61)/CTGF/
NOV (nephroblastoma overexpressed)] family of matricellular signaling modulators that are characterized by four conserved modular domains displaying homology with insulin-like growth factor binding protein, von Willebrand factor type C/chordin-like CR domain, thrombospondin type 1 repeat and cysteine-knot at c-terminus (CT domain) [Abreu et al., 2002b]. Although, it has already been shown that CCN2 is present during Meckel's cartilage and tooth development [Shimo et al., 2002, 2004], the relationship between CCN2 and the TGF $\beta /$ SMAD2/3 signaling cascade during early stages of tooth development remains unclear.

$\mathrm{CCN} 2$ is induced by TGF $\beta 1$ through its unique TGF $\beta$ responsive element [Grotendorst et al., 1996; Leask et al., 2003]. It has been shown that CCN2 is widely expressed in the anterior region of both mouse and Xenopus embryos [Abreu et al., 2002a; Ivkovic et al., 2003]. In mouse, Ccn 2 mRNA is detected in the nasal process, and $\mathrm{Ccn} 2^{-/-}$mice develop craniofacial defects such as domed skull, cleft palate, shortened mandible and absence of the adjacent ethmoid bone [Ivkovic et al., 2003]. In Xenopus, $\mathrm{CCN} 2$ expression occurs in the anterior region of the embryo, being expressed in the nasal placode and branchial arches, and overexpression of $C c n 2$ mRNA induces dorso-anterior phenotypes [Abreu et al., 2002a]. CCN2 directly binds bone morphogenic protein (BMP) 4 and TGF $\beta 1$ through its CR domain [Abreu et al., 2002a]. These interactions result in inhibition of BMP4 activity by preventing binding of BMP to its receptors, and in enhancement of binding of TGF $\beta 1$ to its cognate receptors [Abreu et al., 2002]. In addition, during the tooth placode stage, the expression of BMP inhibitors such as CCN2 is necessary for regular development of the tooth [Pummila et al., 2007].

Considering that both CCN2 and TGF $\beta$ have been shown to participate in tooth development, and that they interact in a great variety of systems, this work was undertaken to investigate the relationship between the TGF $3 /$ Smad signaling pathway and CCN2, and their influence on cell proliferation during early stages of tooth development.

Our results indicate that CCN2 and TGF $/$ SMAD2 signaling components are active in signaling centers during early stages of tooth development and also that the proliferation in these areas displays different profiles for epithelial and mesenchymal cells. Furthermore, activity of the TGF $\beta / S M A D 2$ signaling cascade and proliferation of epithelial and mesenchyme cells are not affected by the absence of CCN2 expression during early stages of tooth development. 


\section{Materials and Methods}

\section{Embryo Preparation}

Pregnant Swiss mice at E11.5, E12.5, E13.5 and E14.5 (noon at the day on which vaginal plug was detected is E0.5) were sacrificed and the heads were dissected and fixed in $4 \%$ paraformaldehyde, dehydrated in crescent concentrations of alcohol $(50,70,80$, 90, 95 and 100\%), treated with xylene and embedded in paraffin.

\section{Generation of $\mathrm{Ccn}^{-/-}$Knockout Mice}

$\mathrm{Ccn} 2^{-/-}$mice were generated as previously described by Ivkovic et al. [2003]. Embryos at stages E13.5 and E18.5 were used in this work. Genotyping was performed as described in Ivkovic et al. [2003].

\section{Cell Proliferation Detection}

5'-Bromo-2'-deoxyuridine (BrdU, Sigma) was administered intraperitoneally $2 \mathrm{~h}$ prior to animal sacrifice, at a concentration of $10 \mathrm{mg} / \mathrm{ml}$ (100 $\mu \mathrm{g} / \mathrm{g}$ body weight). The embryos from E11.5 to E14.5 were dissected and treated as described above. Coronal sections of $4 \mu \mathrm{m}$ were dipped in xylene and alcohol and processed for immunohistochemistry against BrdU. After washing in phosphate-buffered saline (PBS), sections were treated with $2 \mathrm{~N}$ hydrochloric acid and borate buffer at $50{ }^{\circ} \mathrm{C}$. Tissues were treated with normal goat serum (DAKO; 5\% in PBS), and incubated with antibody anti-BrdU (Accurate) overnight. Visualization was accomplished by Cy3-labeled secondary antibody (Molecular Probes), and slides were mounted with 4'-6-diamidino-2-phenylindole. Proliferating cell nuclear antigen (PCNA) immunostaining was performed as describe below. A negative control for the BrdU assay was performed by omitting the primary antibody during immunostaining.

\section{Immunohistochemistry}

Paraffin-embedded heads were sectioned in the coronal plane at $4 \mu \mathrm{m}$ thickness and mounted onto slides. Sections were dipped in xylene to remove the paraffin and dehydrated through a graded alcohol series. In order to prevent endogenous peroxidase activity, sections were incubated with $3 \%$ hydrogen peroxide in methanol for $30 \mathrm{~min}$ at room temperature following sodium citrate antigen unmasking treatment for $20 \mathrm{~min}$ at $96^{\circ} \mathrm{C} .5 \%$ normal goat serum in PBS-Triton (0.3\%) was used for blocking at room temperature. The following antibodies were used: anti-CTGF (1:100, rabbit polyclonal antibody: Torrey Pines Biotechnology); anti-TGF $\beta 1$ (1:50, rabbit polyclonal antibody: Santa Cruz Biotechnology); anti-TGFRII (1:50, rabbit polyclonal antibody; Santa Cruz Biotechnology); anti-Smad2/3 (1:50, goat polyclonal antibody: Santa Cruz Biotechnology); anti-Smad4 (1:50, mouse monoclonal antibody: Santa Cruz Biotechnology); anti-phospho-Smad2 (SMAD2P; 1:500, rabbit polyclonal: Cell Signaling Biotechnology); anti-PCNA (1:100, mouse monoclonal: Accurate); in 5\% normal goat serum at $4 \%$, overnight. After that, the slides were treated with the biotin/extravidin peroxidase staining (Sigma) and developed with diaminobezidine tetrahydrochloride (DAB-Vector Laboratories). The slides were then counterstained with Harris hematoxylin or methyl green and mounted with Entellan (Merck) in order to visualize nuclei of the cells. Negative controls were obtained following the exact protocol described above, but omitting the primary antibody of each reaction. The slides were photo- graphed under a Nikon TE300 microscope. Drawings of the CCN2-staining on tooth sections were performed from the photomicrographs and in Adobe Photoshop. A dot color was used to mark positive cells.

\section{Statistical Analysis}

PCNA- and phospho-SMAD2-stained sections obtained from 4 independent animals ( $\mathrm{C} n 2^{-/-}$vs. wild type, WT) were scored by cell counting under microscopic observation. The number of cells staining positive in each dental tissue was plotted using $\mathrm{Mi}$ crosoft Excel software, and the average and standard deviation were calculated. Statistical analysis was performed to detect the level of significance of the differences using Student's t test.

\section{Results}

\section{CCN2 Expression Is Specifically Detected in Signaling}

Centers during Early Stages of Tooth Development

In order to specifically detect CCN2 expression in tooth elements, we employed an affinity-purified polyclonal antibody in histological sections of E13.5 and E18.5 in WT and $\mathrm{Ccn}^{-/-}$null mice (fig. 1). We could not detect any staining in $\mathrm{Ccn} 2^{-/-}$(fig. $1 \mathrm{~b}$ ), but detected strong staining in the WT section, especially in Meckel's cartilage, a known site of CCN2 expression (fig. 1b). We detected strong CCN2 staining in the dental lamina and inner epithelium of E18.5 WT mice (fig. 1c). However, we did not observe consistent staining in E18.5 WT or in $\mathrm{Ccn} 2$ homozygous mutant $\left(\mathrm{Ccn} 2^{-/-}\right)$sections from which the primary antibody was omitted (fig. 1d, e). This result indicates that the antibody employed in this study specifically recognizes the $\mathrm{CCN} 2$ protein.

We then analyzed CCN2 expression in epithelia and mesenchymal derivatives during the appearance of the signaling centers at the first three stages of tooth development (fig. 2). At E11.5 we detected CCN2 in the oral epithelial thickening, although a few cells were stained in the underlying mesenchyme (fig. 2a, b). At E13.5 CCN2 expression was mostly detected in the condensed mesenchyme (fig. 2c, d), although we detected some cells expressing CCN2 in epithelial bud (fig. 2c, d). At E14.5 CCN2 expression was strongly detected in dental lamina, outer epithelium, inner epithelium, enamel knot and dental sac (fig. 2e, f). We noticed an asymmetric staining in the outer epithelium, which is not detected in all tissues (fig. 2e, f).

These results showed that CCN2 is detected preferentially in the signaling centers during the first three stages of tooth development. 

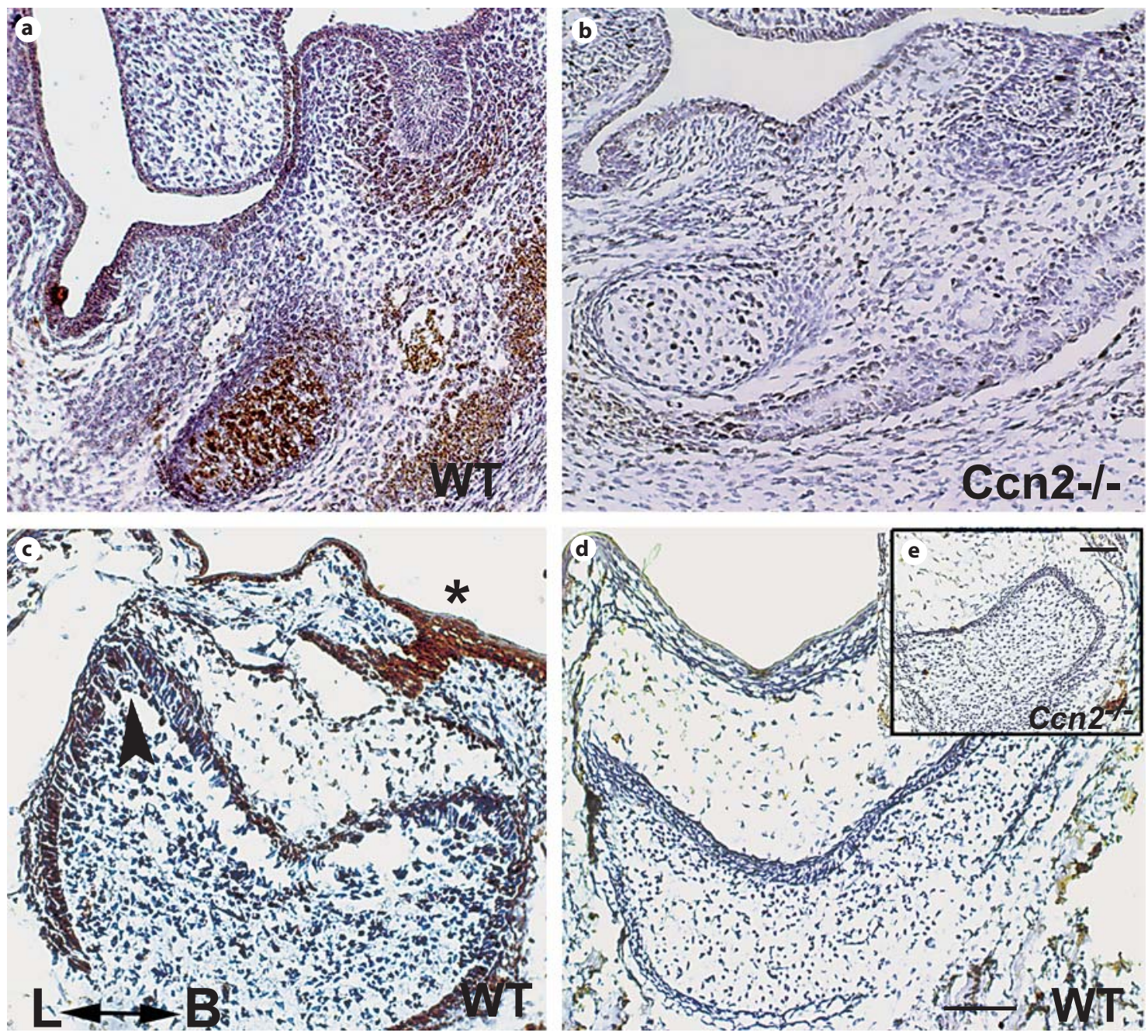

Fig. 1. CCN2 can be specifically detected in dental tissues by immunohistochemistry. a WT molar tooth at E13.5 reacted with anti-CCN2 antibody. CCN2 staining is detected in condensed mesenchyme and in Meckel's cartilage. b CCN2 ${ }^{-/-}$immunostained with anti-CCN2 antibody showing no specific expression. c E18.5 reacted with anti-CCN2 antibody. CCN2 staining is detected in dental lamina (asterisk) and inner epithelium (arrowhead). d Negative reaction where anti-CCN2 polyclonal antibody was omitted showing no specific expression. e Inset showing $\mathrm{Ccn}^{-/-}$at E18.5 when immunostained with anti-CCN2 antibody showing no specific expression. $\mathrm{B}=$ Buccal side; $\mathrm{L}=$ lingual side. Scale bars: $50 \mu \mathrm{m}(\mathbf{a}-\mathbf{d})$ and $100 \mu \mathrm{m}(\mathbf{e})$.

TGF $\beta / S M A D$-Signaling Components Are

Preferentially Expressed in Signaling Centers of

Odontogenesis

Since CCN2 is expressed where inducer centers are present we investigated expression of TGF $\beta 1$ and components of its signaling pathway in three first stages of tooth development in order to compare it with CCN2 expression. TGF $\beta 1$ expression was weakly detected, at E11.5 mainly in the dental lamina, but a few cells in the underlying mesenchyme showed also expression (fig. 3a). At
E13.5 TGF $\beta$ expression was detected mainly in condensed mesenchyme, and a few cells in non-condensed mesenchyme also showed staining (fig. $3 \mathrm{~b}$ ). Tooth bud cells close to the condensed mesenchyme also expressed TGF $\beta 1$ (fig. 3b). At E14.5 TGF $\beta 1$ was expressed in the outer and inner epithelium as well as in the enamel knot, although we also detected some cells in the condensed mesenchyme expressing TGF $\beta 1$ (fig. 3c).

TGFßRII expression was weakly detected in the dental lamina and in the underlying mesenchyme at E11.5, 


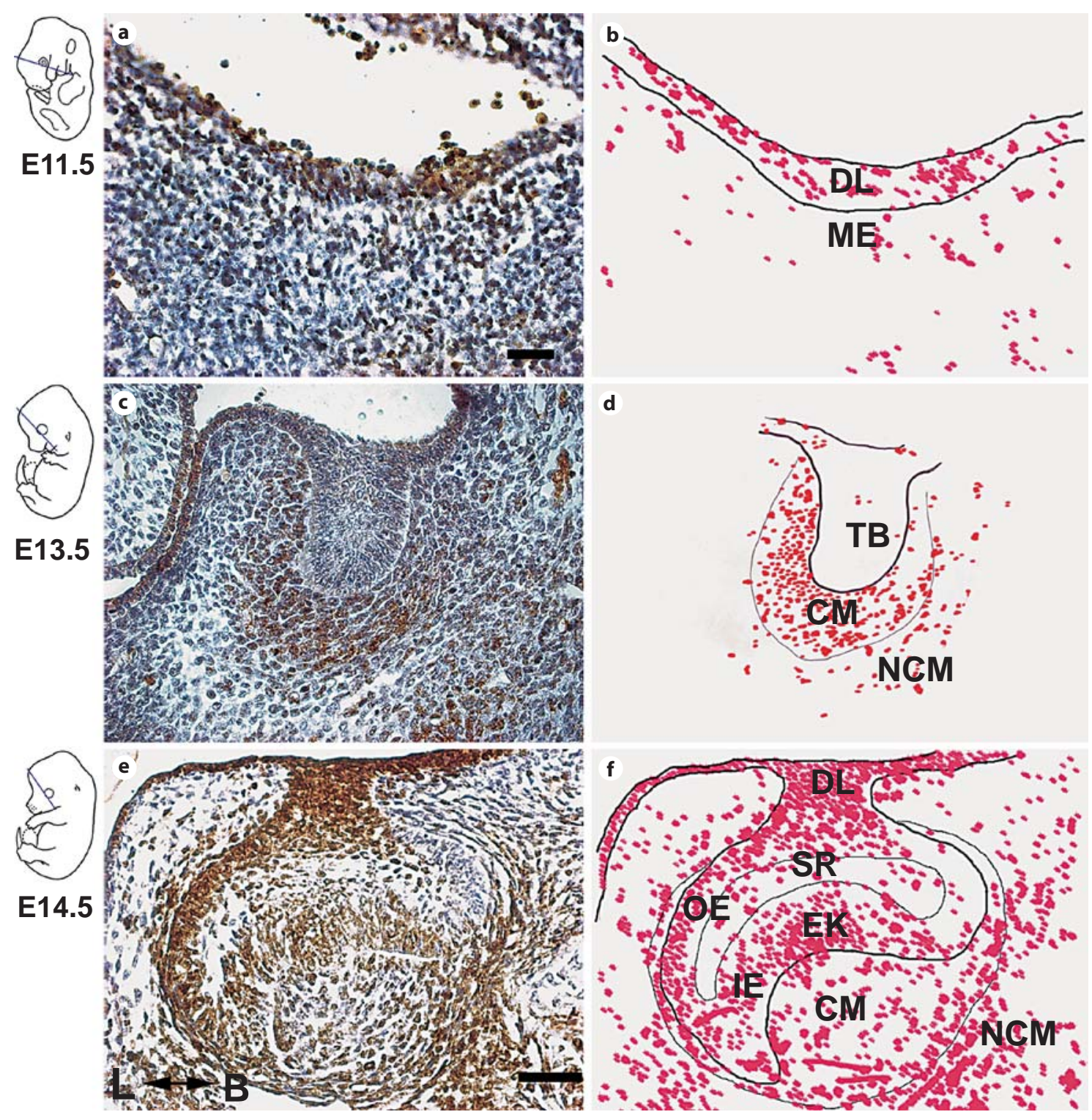

Fig. 2. CCN2 is expressed in signaling centers during early stages of tooth development. a At E11.5 immunostaining is detected in dental lamina and in a few cells in underlying mesenchyme. c At E13.5 (bud stage) staining of CCN2 is detected in condensed mesenchyme around the epithelial bud. Non-dental epithelial cells also express CCN2. Non-condensed mesenchyme appeared almost completely unlabeled. e At E14.5 (cap stage) CCN2 is detected in dental lamina, inner and outer epithelium, enamel knot and dental sac. CCN2 can also be detected in some cells in non-condensed mesenchyme. $\mathbf{b}, \mathbf{d}, \mathbf{f}$ Drawing of the staining shown on the left panels: dots in red indicate cells expressing CCN2. On the left side embryonic stages and section plan is shown. B = Buccal side; $\mathrm{CM}=$ condensed mesenchyme; $\mathrm{DL}=$ dental lamina; $\mathrm{EK}=$ enamel knot; $\mathrm{IE}=$ inner epithelium; $\mathrm{L}=$ lingual side; $\mathrm{ME}=$ mesenchyme; $\mathrm{NCM}=$ non-condensed mesenchyme; $\mathrm{OE}=$ outer epithelium; $\mathrm{SR}=$ stellate reticulum; $\mathrm{TB}=$ tooth bud. Scale bars $=50 \mu \mathrm{m}$.

where a few cells were stained (fig. 3d). At E13.5, TGF$\beta R I I$ expression was detected in condensed mesenchyme as well as in epithelial bud cells (fig. 3e). At E14.5 TGFßRII was expressed similarly to TGF $\beta 1$, occurring in the inner epithelium, outer epithelium and enamel knot. However, in condensed mesenchyme, TGF $\beta$ RII expression looked slightly more abundant than TGF $\beta 1$ (fig. 3f). 

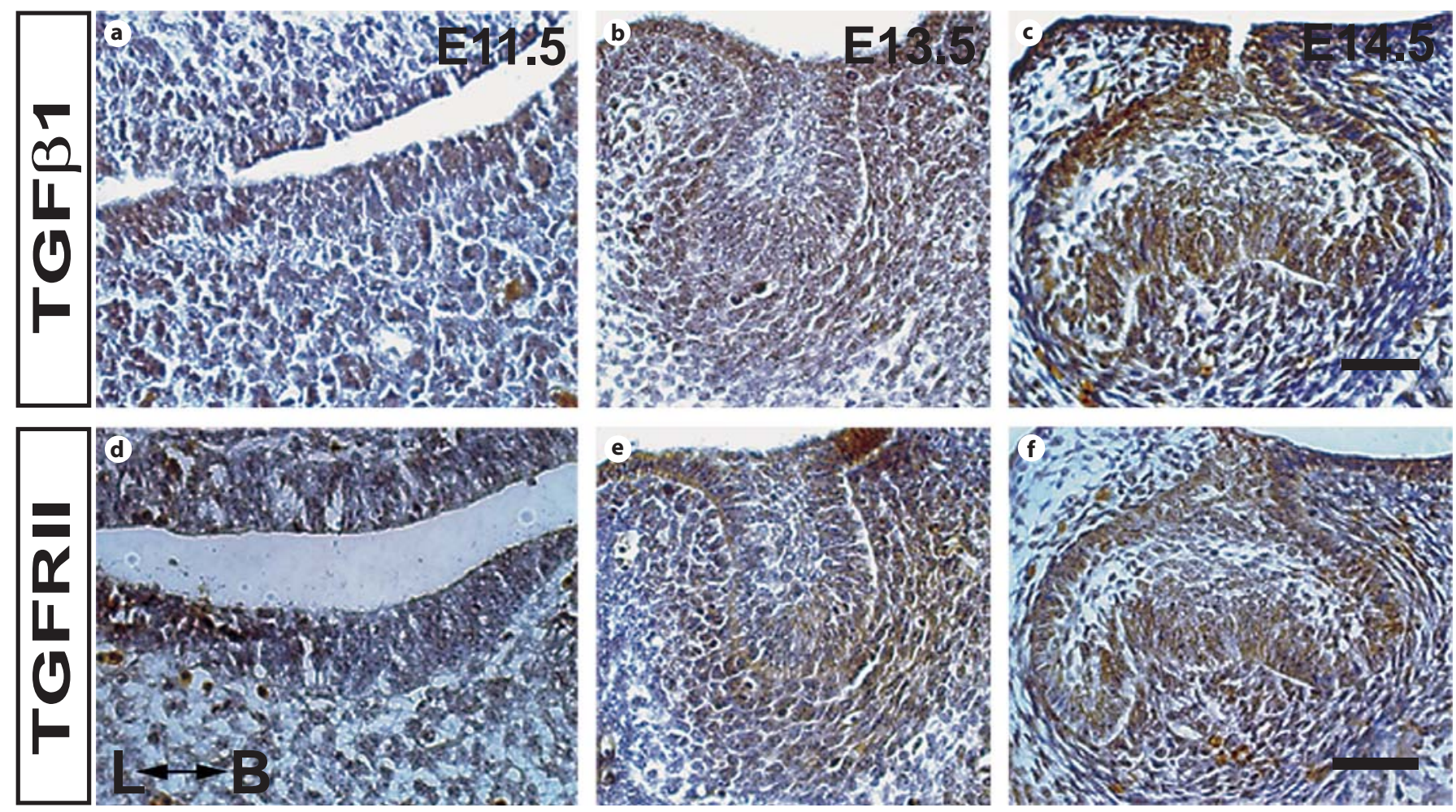

Fig. 3. TGF $\beta 1$ and TGF $\beta$ RII are similarly expressed in signaling centers during early steps of tooth development. At E11.5 TGF $\beta 1$ (a) and TGF $\beta$ RII (d) expression are weakly detected in dental lamina and in a few cells in underlying mesenchyme. At E13.5 TGF $\beta 1$ (b) and TGF $\beta$ RII (e) are expressed in condensed mesenchyme and in cells of the epithelial bud closer to the condensed mesenchyme. At E14.5, TGF $\beta 1$ (c) and TGF $\beta$ RII (f) are highly expressed in inner epithelium, outer epithelium, enamel knot, and are also detected in a few cells in the condensed mesenchyme. $\mathrm{B}=$ Buccal side; $\mathrm{L}=$ lingual side. Scale bars $=50 \mu \mathrm{m}$.

SMAD2/3 expression at E11.5 was strongly detected in the entire dental lamina, but a weaker staining was detected in the mesenchyme around the thickening epithelium (fig. 4a). At E13.5 SMAD2/3 was expressed in all dental tissues, but mostly in the condensed mesenchyme and dental lamina. We also detected weak expression in non-condensed mesenchyme (fig. 4b). At E14.5 the expression of SMAD2/3 was strongly detected in outer epithelium, inner epithelium and enamel knot, but some cells of the stellate reticulum, condensed mesenchyme and non-condensed mesenchyme are also stained (fig. 4c). SMAD4 expression was similar to that of SMAD2/3, but it seemed to be weaker in the mesenchyme underneath and in the thickening of dental lamina at E11.5 (fig. 4d). SMAD4 at E13.5 was detected in all dental tissues, but a few cells in the non-condensed mesenchyme expressed SMAD4 (fig. 4e). At E14.5, similarly to SMAD2/3, SMAD4 expression was detected in the outer epithelium, inner epithelium and enamel knot. We also observed cells of condensed mesenchyme expressing SMAD4 (fig. 4f). This expression analysis showed that TGF $\beta$ RII, SMAD2/3 and SMAD4 are co-expressed during early steps of tooth development indicating that TGF $\beta 1$ signaling can occur at these tissues.

Cell Proliferation Is Dynamic in the Odontogenic Sites

Given that the expression of CCN2 and TGF 31 overlap during early steps of tooth development, we decided to analyze cell proliferation in dental tissues at the stages where CCN2 and TGF $\beta 1$ are expressed. Therefore, we performed BrdU incorporation assay and staining of PCNA. At E11.5 BrdU-positive cells were essentially found to be cells distributed throughout the mesenchyme (fig. 1a, b). PCNA staining revealed a similar pattern of proliferation in the mesenchyme, although we detected some PCNA-positive cells at the epithelium (fig. 1c). At E12.5 proliferation was primarily detected in condensed and non-condensed mesenchyme where BrdU-positive 

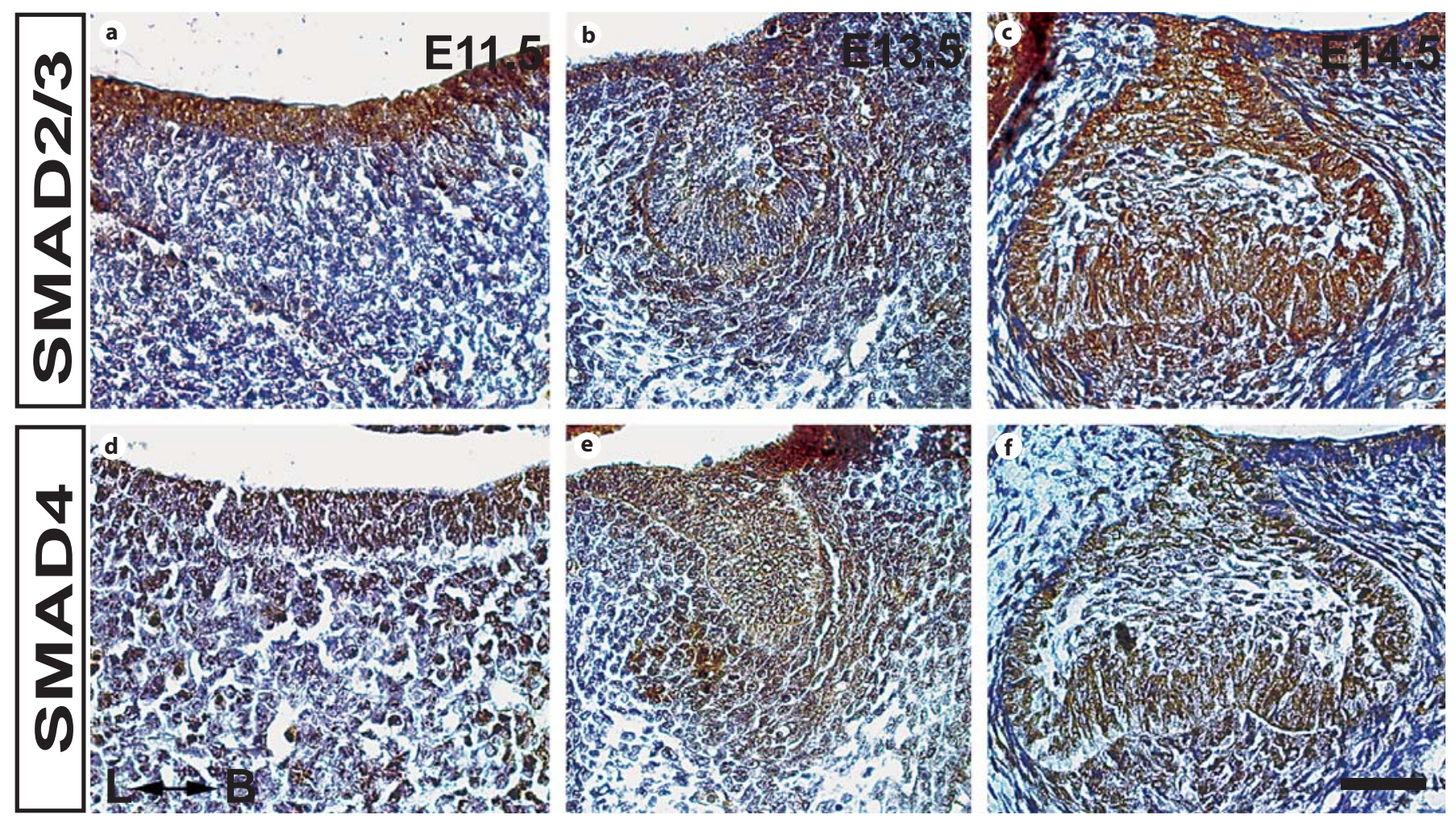

Fig. 4. SMAD2/3 and SMAD4 are similarly expressed in signaling centers during early stages of tooth development. a At E11.5 SMAD2/3 is strongly stained in dental lamina and a few cells can be detected amongst the mesenchymal cells next to the dental lamina. $\mathbf{d}$ SMAD4 expression at E11.5 is mainly detected in dental lamina, however it is weaker than SMAD2/3. SMAD4 is also detected in mesenchymal cells. b At E13.5, SMAD2/3 and SMAD4 (e) expression occurs in condensed mesenchyme and in epithelial bud cells. At E14.5, SMAD2/3 (c) and SMAD4 (f) expression are similarly expressed in outer epithelium, inner epithelium and enamel knot. Weak expression of SMAD2/3 and SMAD4 can be detected in non-condensed mesenchyme and cells of condensed mesenchyme are also stained. $\mathrm{B}=$ Buccal side; $\mathrm{L}=$ lingual side. Scale bar $=50 \mu \mathrm{m}$.

cells could be distinguished and both were similarly proliferating, as could also be observed by PCNA staining (fig. 5d-f). We found many BrdU/PCNA-positive cells in the dental epithelial tissue, markedly in the aggregating cells over the invaginating epithelial bud (fig. $5 \mathrm{~d}$, f). Proliferation in dental epithelial tissue was higher at E12.5 than at E11.5 (fig. 5a-f). At the bud stage (E13.5), we found many BrdU-positive cells in the mesenchyme overlying the epithelial bud (fig. 5g). We also detected BrdU/ PCNA-positive cells in the invaginating bud of the dental epithelia (fig. 5g-i). At E14.5, most of the BrdU-/PCNApositive cells were found in the inner and outer epithelium as compared with other tissues (fig. 5j-1). As previously demonstrated by Vaahtokari et al. [1996], cells of enamel knot were not proliferating (fig. 5j, 1).

These results show that both BrdU and PCNA staining reveals a dynamic proliferation profile in dental epithe- lium and the surrounding mesenchyme during early stages of tooth development. They also showed that from E11.5 to E13.5, proliferation was higher in mesenchyme cells than in dental epithelial cells, however from E13.5 to E14.5 this proliferation profile was inverted.

\section{TGF $\beta / S M A D 2$ Activity and Proliferation Are Not}

Affected in Developing Tooth of $\mathrm{Ccn} 2^{-/-}$Mice

Since we observed that the proliferation profile from E11.5 to E14.5 of the developing tooth was detected in areas in which CCN2 and TGF $\beta 1$ signaling components were detected we decided to analyze the consequences of the lack of CCN2 on SMAD2 phosphorylation and on proliferation. To this end, we immunostained WT and $\mathrm{Ccn} 2^{-/-}$coronal sections for SMAD2P and phosphorylated PCNA at E13.5 and E18.5 (fig. 6). 

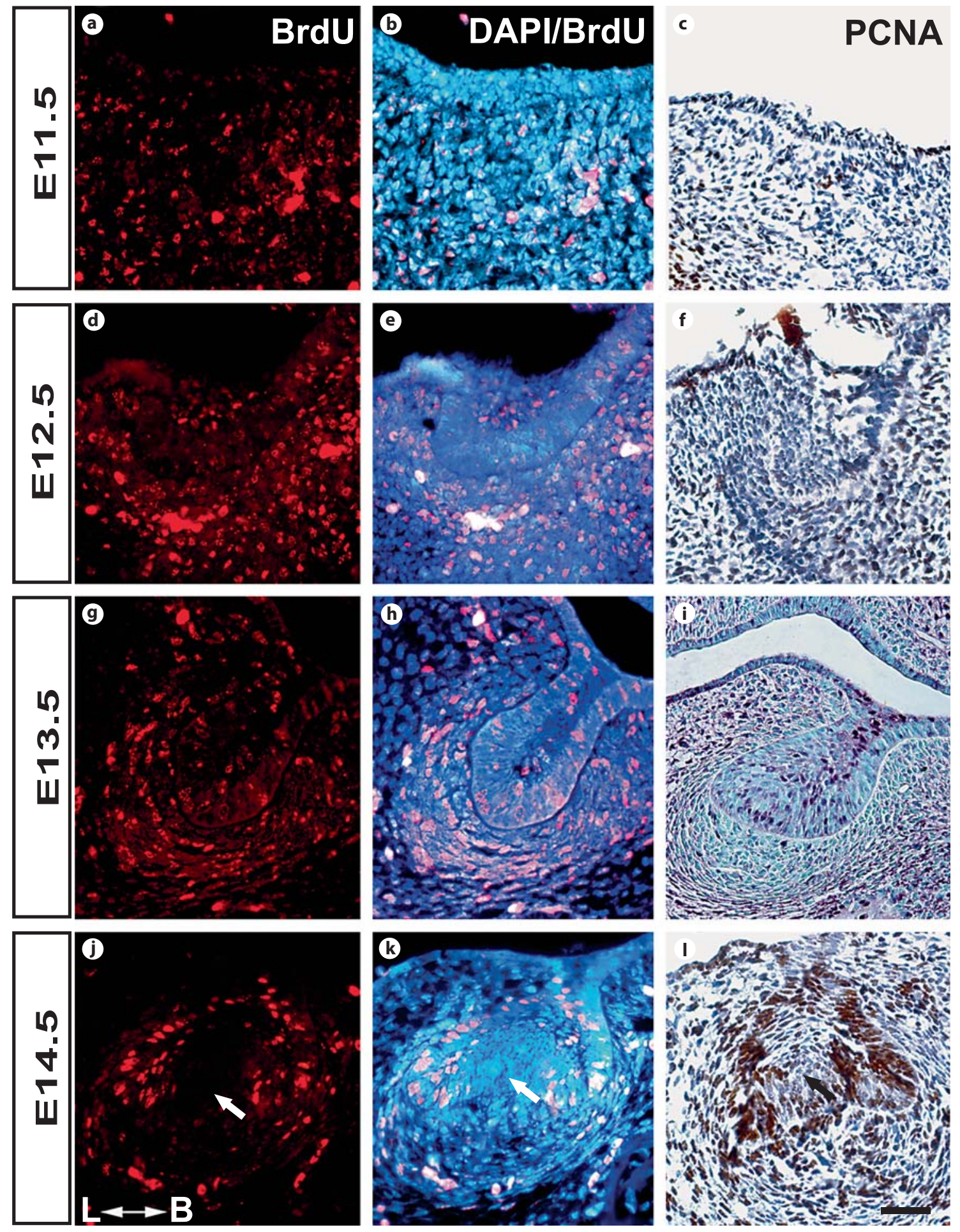

Fig. 5. BrdU and PCNA analysis of cell proliferation during early stages of tooth development. a, b At E11.5 BrdU-positive cells are present in underlying mesenchyme and in a few cells in dental lamina. At this stage, mesenchymal cells show higher proliferation than dental lamina. c Likewise, PCNA staining at E11.5 shows proliferation in dental lamina, and in cells in underlying mesenchyme. d, e At E12.5 expression of BrdU-positive cells is

more prominent in condensed mesenchyme than in invaginating epithelium. f PCNA staining is intensely detected in condensed mesenchyme and can be detected at a lower intensity in invaginating epithelium. $\mathbf{g}, \mathbf{h}$ At $13.5 \mathrm{BrdU}$-positive cells are detected in both epithelial bud and condensed mesenchyme. i PCNA staining confirms the same proliferation profile as the observed in BrdU labeling. Notice that proliferation is not highly detected in non- 
The expression of SMAD2P at E13.5 was mainly detected in cells of the inner region of the epithelial bud as well as in the invaginating cells (fig. 6a). We found more SMAD2P-positive cells in the non-condensed mesenchyme than in condensed mesenchyme (fig. 6a). Comparison of SMAD2P expression in WT and $\mathrm{Ccn}^{-/-}$showed similar expression pattern (fig. 6b). At E18.5 SMAD2P was detected in WT mice and in $\mathrm{Ccn}^{-/-}$teeth mainly in the inner epithelium, stellate reticulum and in cells of condensed mesenchyme (fig. 6e, f). SMAD2P-positive cells were counted and statistical analysis showed that the expression of SMAD2P is not significantly different between WT and $\mathrm{Ccn} 2^{-/-}$animals (data not shown). These results showed that phosphorylation of SMAD2 in cells of E13.5 and E18.5 tooth is not affected in the absence of CCN2.

Although, we have not found differences in theSMAD2 phosphorylation we decided to compare proliferation profiles by PCNA immunostaining of the WT and $\mathrm{Ccn} 2^{-/}$. PCNA was widely expressed in the mesenchyme and in epithelial bud in both WT and $\mathrm{CCn}^{-/-}$mice at E13.5 (fig. 6c, d). At E18.5 the PCNA expression was similarly detected in stellate reticulum, inner epithelium and in condensed mesenchyme in both WT and $\mathrm{Ccn}^{-/-}$animals (fig. 6g, h). PCNA-positive cells from both WT and $\mathrm{Ccn} 2^{-/-}$mice were scored and statistical analysis supports that there is no difference in cell proliferation between $\mathrm{Ccn} 2^{-/-}$and WT in E13.5 and E18.5 teeth.

Morphological comparison between WT and $\mathrm{Ccn} 2^{-/-}$ mutant shows that no difference can be detected in either E13.5 or E18.5 (fig. 6a, b, e, f), which leads us to conclude that the lack of CCN2 does not result in changes in morphology. In both early (E13.5) and late (E18.5) tooth development, no change in tissue organization could be histologically detected. We also checked tooth morphology at E14.5, E16.5 and E17.5, but again, no difference in histologic structure of dental organs could be detected (data not shown).

condensed mesenchyme. j, k At E14.5, BrdU-positive cells are detected in inner and outer epithelium. I Similarly, PCNA staining is also found in inner and outer epithelium, but not in enamel knot cells (arrow). B = Buccal side; DAPI = 4'-6-diamidino-2phenylindole; $\mathrm{L}=$ lingual side. Scale bar $=50 \mu \mathrm{m}$.

TGF $\beta / S M A D 2$ and CCN2 in Tooth

Development

\section{Discussion}

The morphogenesis of the tooth is marked by interaction between epithelial-mesenchymal cells which express a variety of molecules that control cellular commitment, movement and proliferation. Here, we present data showing that CCN2 and components of the TGF $3 / S M A D$ pathway are similarly expressed in odontogenic areas during early stages of tooth development. Although it has been reported that CCN2 and TGF $\beta$ reciprocally modulate their actions, we showed that the lack of CCN2 in mutant mice results in no changes in activity of the TGF $3 / S M A D 2$ signaling pathway and no significant difference in cell proliferation during early tooth development.

Previous studies have already shown that CCN2 is detected during tooth development by immunoreactivity and in situ hybridization [Shimo et al., 2002; Friedrichsen et al., 2003; Yamaai et al., 2005]. While Shimo et al. [2002] did not detect expression of CCN2 in dental lamina, inner and outer epithelia at cap stage and Friedrichsen et al. [2003] found very little RNA message of CCN2 at E14, our results obtained by immunoreactivity of CCN2 protein fill the gaps left by these analyses. Our analysis showed CCN2 expression is quite abundant in the thickening of the oral epithelium, in condensed mesenchyme at the bud stage and in inner and outer epithelium at cap stage, places in which $\mathrm{CCN} 2$ protein may be acting. In addition, our analysis devoted dedicated particular interest to CCN2 expression in signaling center tissues such as dental lamina, condensed mesenchyme and enamel knot, at E11.5, E13.5 and E14.5, respectively.

Since CCN2 is implicated in migration, proliferation and differentiation, it was not surprising to find its expression in signaling centers such as dental lamina, condensed mesenchyme and enamel knot during tooth development. However, our data conflict with other reports that showed perturbations in tooth development, particularly in size and shape when CCN2 is inhibited by antiCCN2 antibody [Shimo et al., 2002]. Our results showed no major difference in size and shape of developing teeth of Ccn2-null mutant mice. One possible explanation for this inconsistency would be that in vivo the action of other molecules from the CCN family could overcome the lack of CCN2 in the mutant mice.

As with CCN2, the TGF $\beta$ signaling cascade also mediates many cellular processes [Massague, 1998]. The presence of TGF $\beta$ and components involved in its signaling pathway such as TGF $\beta$ RII, SMAD2/3 and SMAD4 in dental tissues strongly support the hypothesis that tooth

Cells Tissues Organs 2008;187:199-210 

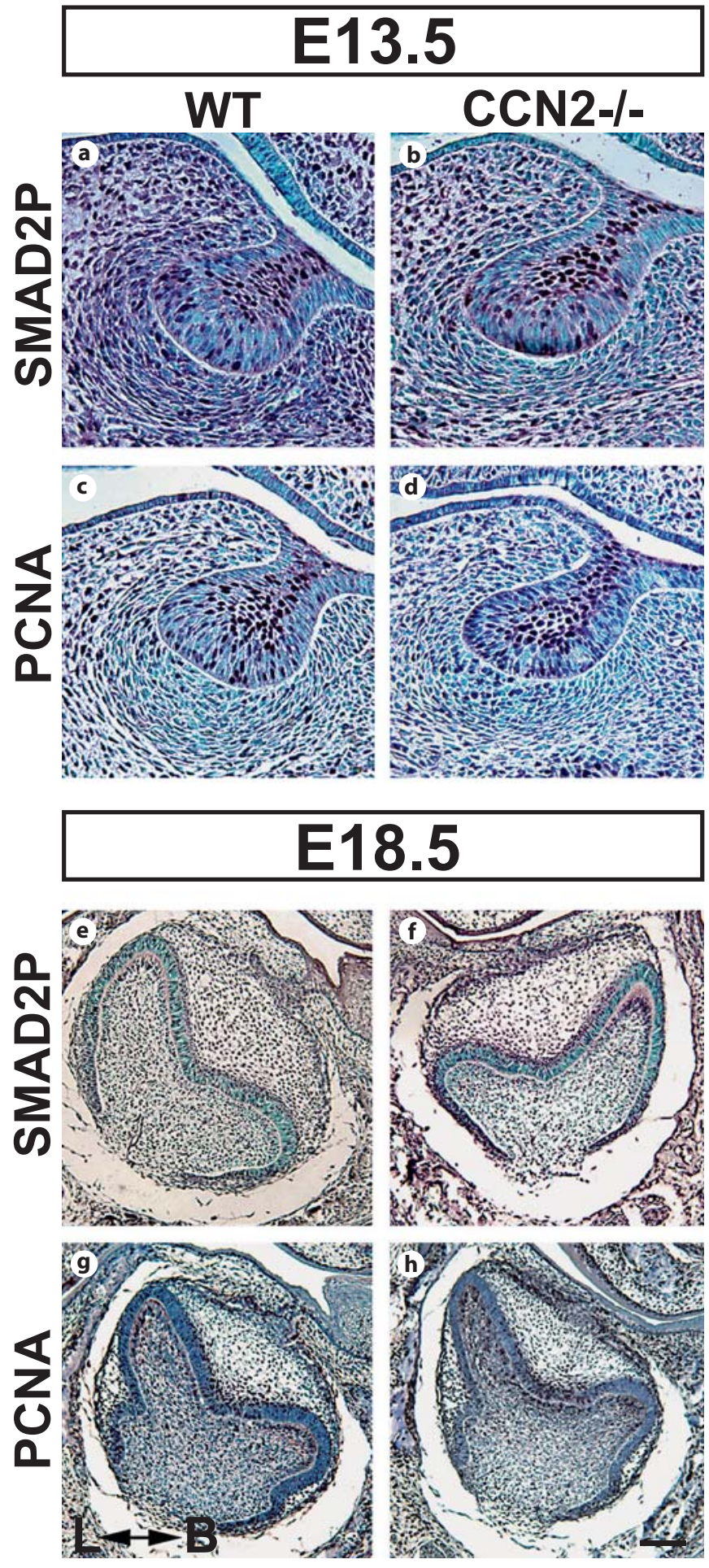

Fig. 6. SMAD2 phosphorylation and proliferation is not affected in $\mathrm{Ccn} 2^{-/-}$. At E13.5, SMAD2P in both WT (a) and Ccn2 $2^{-/-}(\mathbf{b})$ is detected in invaginating epithelial cells and in condensed and non-condensed mesenchyme cells. PCNA staining in WT (c) and $\mathrm{Ccn2}^{-/-}$(d) is mainly detected in epithelium and in non-condensed mesenchyme but a few cells can be detected in condensed mesenchyme. At E18.5 SMAD2P is detected in stellate reticulum, development is dependent upon the TGF $\beta$ pathway, particularly in controlling proliferation and overall growth of tooth [Heikinheimo et al, 1993; Chai et al., 1994, 1999; Ferguson et al., 2001]. Abrogation of TGFßRII increased cell proliferation in tooth cultures at E11.5, indicating that TGF $\beta$ is involved in negative control of tooth development [Chai et al., 1999]. Antagonistic effects of SMAD2 and SMAD7 were detected during tooth development. Attenuation of SMAD2 gene expression resulted in significant advancement of embryonic tooth development with increased proliferation of enamel organ epithelial cells. In this context, we found that CCN2 and TGF $\beta$ / SMAD signaling components are expressed in regions of odontogenic potential.

The interactions between CCN2 and TGF $\beta$ have already been shown in studies that demonstrated increases in $C c n 2 \mathrm{mRNA}$ and protein produced in mouse AKR 2B cells or human fibroblasts after treatment with TGF $\beta$ [Brunner et al., 1991; Igarashi et al., 1993]. In addition, according to Abreu et al. [2002a], CCN2 enhances TGF $\beta 1$ signaling by increasing binding to its cognate receptor and SMAD2/3 phosphorylation, particularly when TGF $\beta 1$ concentration is in the picomolar range [Abreu et al., 2002a]. Using $C c n 2^{-/-}$mice, we were able to show that lack of CCN2 is not correlated with alterations in the TGF $\beta$ pathway output, evidenced by lack of a detectable difference in SMAD2 phosphorylation which could result from the fact that both TGF $\beta 1$ and TGF $\beta R I I$ are abundantly detected in epithelial/mesenchymal tissue of the developing tooth.

CCN2 and TGF $\beta / S M A D$ were detected in signaling centers, and therefore could be implicated in the regulation of proliferation. In order to correlate $\mathrm{CCN} 2$ and TGF $\beta / S M A D$ pathway presence in signaling centers with cell proliferation we combined BrdU assay and PCNA staining. The results show that proliferation occurs in regions adjacent to tissues that act as inducers, suggesting that this induction promotes cell proliferation. At E11.5, the expression of CCN2 and TGF $\beta / S M A D$ detected in dental lamina suggests that these pathways have the potential to proliferation induction in both epithelium and

inner epithelium and mesenchyme cells in WT (e) and Ccn $2^{-/-}(\mathbf{f})$. PCNA staining is mainly detected in stellate reticulum, but is less abundant in mesenchymal cells in both WT (g) and Ccn $2^{-/-}(\mathbf{h})$. Notice that no significant difference in SMAD2P and PCNA staining is found when WT is compared with $C c n 2^{-/-}$. B = Buccal side; $\mathrm{L}=$ lingual side. Scale bar $=50 \mu \mathrm{m}$. 
mesenchyme. However, we detected higher levels of proliferation in mesenchyme (fig. 5b, c), consistent with the observation that shaping is the more relevant event in epithelium at this stage [Zhang et al., 2005]. At E13.5, the odontogenic potential is present in the condensed mesenchyme, where CCN2 and TGF $\beta / S M A D$ are expressed, and we can see that the BrdU-positive cells are induced in both epithelium and condensed mesenchyme itself. At E14.5, the enamel knot expresses CCN2 and TGF $\beta$ / SMAD, and this region does not proliferate, but induces adjacent tissues such as inner and outer epithelium.

Considering that $\mathrm{CCN} 2$ has been shown to be important for proliferation, we analyzed proliferation by PCNA staining comparing WT and $\mathrm{Ccn} 2^{-/-}$mice and observed that in $\mathrm{Ccn} 2^{-/-}$animals, proliferation was not changed in epithelial tooth tissue during development. Interestingly, dental tissue cell proliferation in $\mathrm{Ccn} 2^{-/-}$mice was expected to be reduced according to the proposed mitogenic role of CCN2 [Shimo et al., 2002], but again no consistent difference could be observed in this tissue. Indeed, $\mathrm{Ccn} 2^{-/-}$mouse teeth show no considerable changes in size or shape when compared to WT mice at early (E13.5) and at late stages (E18.5). In stages between E13.5 and E18.5 we could also not detect any difference in morphology (data not shown). One can speculate that the lack of CCN2 could be masked by a compensatory effect of a related factor, especially those of the other CCN family members, which exhibit great protein homology. Furthermore, the differences between the findings in this paper compared with other published results could be due to cross-reactivity of CCN2 antibody with another similar protein, including other $\mathrm{CCN}$ family members.

In summary, these results strongly support that CCN2 and TGF $\beta / S M A D$ signaling pathways may be active in signaling centers of tooth development, but lack of CCN2 does not modulate TGF $\beta / \mathrm{SMAD}$ signaling, or cause changes in developing tooth as observed in in situ/in vitro assays.

\section{Acknowledgments}

We thank Dr. Flavia Gomes for kind gifts of the antibodies against SMAD2/3 and SMAD4, Adiel Batista for animal care and Robert Pogue and Bonny Lee for proof-reading. This work was supported by the Conselho Nacional de Desenvolvimento Científico e Tecnológico, Fundação Carlos Chagas Filho de Amparo à Pesquisa do Estado do Rio de Janeiro, Programa de Núcleos de Excelência and Coordenação de aperfeiçoamanto de pessoal de nível superior.

\section{References}

Abdollah, S., M. Macias-Silva, T. Tsukazaki, H. Hayashi, L. Attisano, J.L. Wrana (1997) TGFßRI phosphorylation Smad2 on Ser465 and Ser467 is required for Smad2-Smad4 complex formation and signaling. J Biol Chem 272: 27678-27685.

Abreu, J.G., C. Coffinier, J. Larraín, M. Oelgeschlager, E.M. De Robertis (2002a) Chordinlike CR and the evolutionarily conserved extracellular signaling system. Gene 287: $39-47$.

Abreu, J.G., N.I. Ketpura, B. Reversade, E.M. De Robertis (2002b) Connective-tissue growth factor (CTGF) modulates cell signaling by BMP and TGF- 3 . Nat Cell Biol 4: 599-604.

Bork, P. (1993) The modular architecture of a new family of growth regulators related to connective tissue growth factor. FEBS Lett 327: 125-130.

Brunner, A., J. Chinn, M. Neubauer, A.F. Purchio (1991) Identification of a gene family regulated by transforming growth factor- $\beta$. DNA Cell Biol 10: 293-300.
Chai, Y., A. Mah, C. Crohin, S. Groff, P. Bringas, Jr., T. Le, V. Santos, H.C. Slavkin (1994) Specific transforming growth factor- $\beta$ subtypes regulate embryonic mouse Meckel's cartilage and tooth development. Dev Biol 162: 85-103.

Chai, Y., J. Zhao, A. Mogharei, B. Xu, P. Brigas, Jr., C. Shuler, D. Warburton (1999) Inhibition of transforming growth factor- $\beta$ type II receptor signaling accelerates tooth formation in mouse first branchial arch explants. Mech Dev 86: 63-74.

Chai, Y., Y. Ito, J. Han (2003) TGF-beta signaling and its functional significance in regulating the fate of cranial neural crest cells. Crit Rev Oral Biol Med 14: 78-88.

Ferguson, C.A., A.S. Tucker, K. Heikinheimo, M. Nomura, P. Oh, E. Li, P.T. Sharpe (2001) The role of effectors of the activin signaling pathway, activin receptors IIA and IIB, and Smad2, in patterning of tooth development. Development 128: 4605-4613.

-Fitzpatrick, D.R., F. Denhez, P. Kondaiah, R.J. Akhurst (1990) Differential expression of TGF- $\beta$ in murine palatogenesis. Development 109:585-595.
Friedrichsen, S., H. Heuer, S. Christ, M. Winckler, D. Brauer, K. Bauer, G. Raivich (2003) CTGF expression during mouse embryonic development. Cell Tissue Res 312: 175-188.

Grotendorst, G.R., H. Okochi, N. Hayashi (1996) A novel transforming growth factor beta response element controls the expression of the connective tissue growth factor gene. Cell Growth Differ 7: 469-480.

Heikinheimo, K., R.P. Happinen, P.J. Miettinen, O. Ritvos (1993) Transforming growth factor $\beta 2$ in epithelial differentiation of developing teeth and odontogenic tumors. J Clin Invest 91: 1019-1027.

-Heldin, C.H., K. Miyazono, P.T. Dijke (1997) TGF- $\beta$ signaling from cell membrane to nucleus through SMAD proteins. Nature 390: 465-471.

Igarashi, A., H. Okachi, D.M. Bradham, G.R. Grotendorst (1993) Regulation of connective tissue growth factor gene expression in human skin fibroblasts and during wound repair. Mol Biol Cell 4: 637-645. 
Ito, Y., Zhao, J., A. Mogharei, C.F. Shuler, M. Weinstein, C. Deng, Y. Chai (2001) Antagonistic effects of Smad 2 versus Smad7 are sensitive to their expression level during tooth development. J Biol Chem 276: 4416344172.

Ivkovic, S., B.S. Yoon, S.N. Popoff, F.F. Safadi, D.E. Libuda, R.C. Stephenson, A. Daluiski, K.M. Lyons (2003) Connective tissue growth factor coordinates chondrogenesis and angiogenesis during skeletal development. Development 130: 2779-2791.

Leask, A., A. Holmes, C.M. Black, D.J. Abraham (2003) Connective tissue growth factor gene regulation. Requirements for its induction by transforming growth factor- $\beta_{2}$ in fibroblasts. J Biol Chem 278: 13008-13015.

-Massague, J. (1998) TGF-beta signal transduction. Annu Rev Cell Biol 67: 753-791.

Massague, J., A. Hata, F. Liu (1997) TGF- $\beta$ signaling through the Smad pathway. Trends Cell Biol 7: 187-192.

-Millan, F.A., F. Donhez, P. Kondaiah, R.J. Akhurst (1991) Embryonic gene expression of TGF- $\beta 1,2,3$ suggest different development functions in vivo. Development 111: 131-143.

Mina, M., E.J. Kollar (1990) The induction of odontogenesis in non-dental mesenchyme combined with early murine mandibular arch epithelium. Arch Oral Biol 32:123-127.
Moussad, E.A., D.R. Brigstock (2000) Connective tissue growth factor: what's in a name? Mol Genet Metab 71: 276-292.

-Nakao, A., T. Imamura, S. Souchelnytskyi, M. Kawabata, A. Ishisaki, E. Oeda, K. Tamaki, J. Hanai, C.H. Heldin, K. Miyazono, P. ten Dijke (1997) TGF-beta receptor-mediated signaling through Smad2, Smad3 and Smad4. EMBO J 16: 5353-5362.

Peters, H., R. Balling (1999) Teeth. Where and how to make them. Trends Genet 15: 59-65.

- Pummila, M., I. Fliniaux, R. Jaatinen, M.J. James, J. Laurikkala, P. Schneider, I. Thesleff, M.J. Mikkola (2007) Ectodysplasin has a dual role in ectodermal organogenesis: inhibition of Bmp activity and induction of Shh expression. Development 134: 117-125.

Sharpe, P.T. (2001) Neural crest and tooth morphogenesis. Adv Dent Res 15: 4-7.

Shimo, T., C. Wu, P.C. Billings, R. Piddington, J. Rosenbloom, M. Pacifici, E. Koyama (2002) Expression, gene regulation, and roles of Fisp12/CTGF in developing tooth germs. Dev Dyn 224: 267-278.

Shimo, T., M. Kanyama, C. Wiu, H. Sugito, P.C. Billings, W.R. Abrams, J. Rosenbloom, M. Iwanoto, M. Pacifici, E. Koyama (2004) Expression and roles of connective tissue growth factor in Meckel's cartilage development. Dev Dyn 231: 136-147.

Thesleff, I. (2003) Epithelial-mesenchymal signaling regulating tooth morphogenesis. J Cell Sci 116: 1647-1648.
Vaahtokari, A., T. Aberg, J. Jernvall, S. Keranen, I. Thesleff (1996) The enamel knot as a signaling center in the developing mouse tooth. Mech Dev 54: 39-43.

Wrana, J.L., L. Attisano, R. Wieser, F. Ventura, J. Massague (1994) Mechanisms of activation of the TGF- $\beta$ receptor. Nature 370: 341-347.

Wu, J.W., M. Hu, J. Chai, J. Seoane, M. Huse, C. Li, D.J. Rigotti, S. Kyin, T.W. Muir, R. Fairman, J. Massague, Y. Shi (2001a) Crystal structure of a phosphorylated Smad2. Recognition of phosphoserine by $\mathrm{MH} 2$ domain and insights on Smad function in TGF-beta signaling. Moll Cell 8: 1277-1289.

Wu, J.W., R. Fairman, J. Penry, Y. Shi (2001b) Formation of a stable heterodimer between Smad2 and Smad4. J Biol Chem 276: 2068820694.

-Yamaai, T., T. Nakanishi, M. Asano, K. Nawachi, G. Yoshimichi, K. Ohyama, T. Komori, T. Sugimoto, M. Takigawa (2005) Gene expression of connective tissue growth factor (CTGF/CCN2) in calcifying tissues of normal and cbfa1-null mutant mice in late stage of embryonic development. J Bone Miner Metab 23: 280-288.

Zhang, Y.D., Z. Chen, Y.Q. Song, C. Liu, Y.P. Che (2005) Making a tooth: growth factors, transcription factors, and stem cells. Cell Res 15: 301-316. 